\title{
Dermoscopy of Cutaneous Graft-Versus-Host-Disease in Patients After Allogeneic Hematopoietic Stem Cell Transplantation
}

\author{
Grażyna Kaminska-Winciorek (D) · Iris Zalaudek • Włodzimierz Mendrek • \\ Magdalena Jaworska · Maksymilian Gajda · Jerzy Hołowiecki • \\ Jan Szymszal · Sebastian Giebel
}

Received: June 3, 2020 / Published online: July 16, 2020

(C) The Author(s) 2020

\section{ABSTRACT}

Introduction: Progress in the transplant procedure has resulted in a higher proportion of patients with long-term survival after allogeneic hematopoietic stem cell transplantation (alloHSCT). Cutaneous graft-versus-host disease (GvHD) occurs often among patients who have

Digital features To view digital features for this article go to https://doi.org/10.6084/m9.figshare.12589175.

G. Kaminska-Winciorek (凶) · W. Mendrek .

J. Hołowiecki · S. Giebel

Department of Bone Marrow Transplantation and

Onco-Hematology, Maria Sklodowska-Curie

National Research Institute of Oncology

(MSCNRIO), Gliwice, Poland

e-mail: dermatolog.pl@gmail.com

\section{Zalaudek}

Department of Dermatology and Venereology, Ospedale Maggiore, University of Trieste, Trieste, Italy

\section{Jaworska}

Department of Pathology, Maria Sklodowska-Curie National Research Institute of Oncology

(MSCNRIO), Gliwice, Poland

M. Gajda

Department of Epidemiology, School of Medicine in Katowice, Medical University of Silesia, Katowice, Poland

J. Szymszal

Faculty of Technical Sciences, University of

Occupational Safety Management, Katowice, Poland undergone allo-HSCT. Routine diagnosis of skin and mucosal lesions is based primarily on clinical evaluation and histopathologic confirmation of skin biopsies. However, biopsy is an invasive method and histopathologic analysis is time-consuming, often accompanied by a lack of clinical correlation. There is therefore an urgent need for non-invasive, reproducible in vivo imaging methods that could be used in patients with cutaneous GvHD-both in the setting of initial diagnosis and during followup.The aim of the study reported here was to determine the role of dermoscopic monitoring of skin lesions in allo-HSCT recipients with consecutive histopathologic support as a noninvasive, alternative method to diagnose GvHD. Methods: Twenty patients were examined by dermoscopy upon the manifestation of skin changes in the course of GvHD. Consecutive skin biopsies for histopathologic analysis were obtained from the suspected skin locations determined during dermoscopy.

Results: Graft-versus-host disease was confirmed by histopathology in 19 of the 20 alloHSCT recipients. Four patients developed symptoms of acute cutaneous GvHD (grade 1, $n=2$; grade $2, n=1$; grade $3, n=1$ ), and 15 patients developed chronic cutaneous GvHD. The most frequent dermoscopic signs (irrespective of whether GvHD was chronic or acute) were vessels and scaling (both $n=14,73.7 \%$ ). Hyperpigmentation and white patchy areas were present in eight patients (42.1\%). Fair to 
moderate levels of agreement were found between presence of melanophages in the skin sample and dermoscopic granularity (Cohen's Kappa $[\kappa]=0.39)$, scaling $(\kappa=-0.3)$ and vessels $(\kappa=-0.42)$. The finding of white patchy areas was inversely associated with lymphocytic infiltration $(\kappa=-0.55)$.

Conclusion: The results of this study suggest that dermoscopy may be a useful tool for diagnosing cutaneous GvHD in allo-HSCT recipients. Combining the clinical picture with dermoscopic features may bring us closer to a faster and easier diagnosis of GvHD.

Keywords: Cutaneous graft-versus-hostdisease; Dermoscopy; Hematopoietic allogeneic stem cell transplantation

\section{Key Summary Points}

Why carry out this study?

Cutaneous graft-versus-host-disease (GvHD) is one of the most common complications in allogeneic hematopoietic stem cell transplantation (allo-HSCT) recipients. The acute form may be life-threatening, while the chronic form may lead to severe disabilities.

Clinical and histopathologic evaluation remain the golden standard for GvHD diagnosis.

There is an urgent need for a non-invasive diagnostic method that can be used in the setting of initial diagnosis and follow-up.

\section{What was learned from the study?}

Dermoscopic features (granularity, scaling, white patchy areas and the presence of linear vessels) may be a surrogate for selected histopathologic signs of GvHD.

Dermoscopy can be used as a non-invasive diagnostic tool in the screening of alloHSCT recipients showing signs of cutaneous GvHD.

\section{INTRODUCTION}

Progress in the transplant procedure has resulted in a higher proportion of patients with longterm survival after transplantation. However, the transplant procedure still involves a significant risk of complications.

Acute graft-versus-host-disease (AGvHD) occurs in $40-70 \%$ of allogeneic hematopoietic stem cell transplantation (allo-HSCT) recipients and is the major cause of short-term (100 day) mortality [1]. AGvHD is manifested by one or more of the following features: erythematous skin lesions, cholestatic liver disease and gastrointestinal disturbances [1]. Skin manifestations vary and may include erythematous maculopapular rash, which may be pruritic or painful and, in severe cases, become bullous with subsequent desquamation [1]. The classification of AGvHD is based on the Glucksberg scale in which each organ is staged from 0 to 4 [1], with the stage of skin lesions based on the presence of maculopapular rash and the size of the affected body surface area (e.g. $<25 \%$ in stage $1,25-50 \%$ in stage 2 ). In more advanced cases, generalized erythroderma (stage 3) is present, which subsequently may lead to bullae with desquamation (stage 4) [1]. The scores for all stages are combined to produce an overall grade (from I to IV) depending on the organ and stage of involvement [1].

Chronic GvHD (cGvHD) affects $30-70 \%$ of allo-HSCT recipients and remains the leading cause of mortality not attributable to cancer recurrence [2]. Historically, chronic cutaneous GvHD (CGvHD) was classified as limited or extensive [3]. The National Institutes of Health (NIH) global scoring system includes two components, namely each organ system (skin, mouth, eyes, gastrointestinal tract, liver, lungs, joints, fascia, female genital tract) and the number of affected sites/organs [1]. New diagnostic staging criteria of cGvHD were established in 2005 [4] and modified in 2014 [5]. The consensus group defined diagnostic signs of CGvHD (in the presence of any of these signs no further investigation is needed for the confirmation of CGvHD), distinctive signs (should be confirmed by biopsy), other features of cGvHD 
which are not specific and common signs that occur both in chronic and acute GvHD [1, 3].

Choosing the appropriate therapy, requires a quick and reliable diagnosis, which is currently based mainly on the histopathologic evaluation of the skin biopsy. Due to the invasive nature of the biopsy and the lack of its use in monitoring the response to treatment, it is urgent that new methods that could facilitate the diagnosis and further evaluation of patients be developed. In this context and given the high frequency of CGvHD in hematologic practice, dermoscopy can be regarded as a new routine diagnostic method [6].

The aim of this study was to identify the characteristic dermoscopic features of typical skin lesions in GvHD that can enable the detection of changes in the skin, with the possibility dermoscopic confirmation at every stage of the disease.

\section{METHODS}

\section{Patients}

Twenty patients aged $>18$ years who received allo-HSCT were included in the study. The transplant procedures were performed in the Department of Bone Marrow Transplantation and Oncohematology in Gliwice, Poland. The study protocol was approved by the Local Ethics Committee (KB/43041/13). All patients gave written informed consent. Details of patients' and donors' characteristics are shown in Table 1.

\section{Clinical Evaluation}

Twenty patients were subjected to dermoscopy with first appearance of skin changes. Clinical grading of AGvHD was based on Glucksberg criteria [1]. An infectious etiology was excluded in all cases of acute skin lesions based on clinical symptoms, microbiology, viral tests and laboratory assessment [6]. The presence of cytomegaloviremia (CMV) in the serum was excluded by PCR analysis (performed routinely in all patients every week after transplantation). In addition, all patients who received stem cells from unrelated donors were also monitored for Epstein-Barr virus (EBV) every week. Consequently, all patients were CMV- and EBV-negative. Chronic GvHD was classified on the basis of "diagnostic," "distinctive," "other" and "common" features as defined in the NIH consensus group guidelines [1, 3-5]. Diagnostic clinical features of CGvHD include poikiloderma, lichen planus-like eruption, deep sclerotic features, morphea-like changes and lichen sclerosus-like lesions. Distinctive features include depigmentation (vitiligo) and papulosquamous lesions. Other features, including ichthyosis, keratosis pilaris, hypopigmentation and hyperpigmentation, are also taken into account [5].

\section{Histopathology}

The target area for dermoscopic assessment was the site of the most representative lesion. This assessment was followed by consecutive dermoscopically-guided skin biopsy, according to recommendations of Hillen et al. [7]. Dermoscopic assessment and biopsy at the same location were carried out at the time of the diagnosis of the skin changes, prior to the initiation of any treatment. In the histopathologic examination standard stains with hematoxylin and eosin were used, and the specimens were analyzed by a qualified histopathologist. The histopathologic reports were prepared in concordance with NIH recommendations by Shulman et al. (no GvHD, possible GvHD or likely GvHD) [8]. In AGvHD cases, modified Lerner's grading was applied (grade 1-4) [9].

\section{Transplantation Procedure}

Sixteen patients received conditioning treatment based on irradiation (2-12 Gy) while the remaining four patients were treated with chemotherapy alone (Table 1). The conditioning regimen was myeloablative in 17 patients, and three patients were treated with a nonmyeloablative conditioning regimen. All patients undergong an unrelated donor transplant were treated with antithymocyte globulin. Peripheral blood was the source of stem cells. 
Table 1 Patient and donor characteristics and transplantation procedure

\begin{tabular}{|c|c|c|c|}
\hline \multicolumn{2}{|l|}{ Patient and donor characteristics } & \multicolumn{2}{|l|}{ Transplantation procedures } \\
\hline Patient and donor characteristics & Values & Transplantation procedure & Values \\
\hline Median patient age, years (range) & $36(23-64)$ & Type of conditioning regimen, $n(\%)$ & \\
\hline Median donor age, years (range) & $29(19-66)$ & Irradiation based & $16(80 \%)$ \\
\hline $\begin{array}{l}\text { Median time from diagnosis to } \\
\text { transplantation, years (range) }\end{array}$ & $1.17(0.35-8.96)$ & Chemotherapy based & $4(20 \%)$ \\
\hline Donor/patient gender, $n(\%)$ & & Myeloablative & $17(85 \%)$ \\
\hline Male/male & $5(25 \%)$ & Reduced intensity & $3(15 \%)$ \\
\hline Male/female & $2(10 \%)$ & Stem cell source, $n(\%)$ & \\
\hline Female/male & $8(40 \%)$ & Peripheral blood & $19(95 \%)$ \\
\hline Female/female & $5(25 \%)$ & Peripheral blood and bone marrow & $1(5 \%)$ \\
\hline Donor/patient CMV status, $n(\%)$ & & Transplanted cells & \\
\hline Negative/negative & $1(5 \%)$ & Median CD $34(+) \times 10^{6} / \mathrm{kg}$ (range) & $7.02(1.5-14.8)$ \\
\hline Negative/positive & $3(15)$ & Median CD $3(+) \times 10^{7} / \mathrm{kg}$ (range) & $22.83(11.5-50.2)$ \\
\hline Positive/negative & $2(10 \%)$ & GvHD prophylaxis, $n(\%)$ & \\
\hline Positive/positive & $14(70 \%)$ & CsA/short course & $19(95 \%)$ \\
\hline Donor, $n(\%)$ & & No prophylaxis & $1(5 \%)$ \\
\hline HLA-identical sibling & $10(50 \%)$ & & \\
\hline Matched unrelated & $7(35 \%)$ & & \\
\hline Mismatched unrelated & $2(10 \%)$ & & \\
\hline Haploidentical & $1(5 \%)$ & & \\
\hline \multicolumn{4}{|l|}{ Diagnosis, $n$} \\
\hline AML & 6 & & \\
\hline ALL & 3 & & \\
\hline CML & 1 & & \\
\hline MDS & 2 & & \\
\hline Mycosis fungoides/Sezary syndrome & 1 & & \\
\hline Hodgkin lymphoma & 4 & & \\
\hline Multiple myeloma & 1 & & \\
\hline Lymphoblastic lymphoma & 1 & & \\
\hline Anaplastic lymphoma & 1 & & \\
\hline
\end{tabular}

$A L L$ Acute lymphoblastic leukemia, $A M L$ acute myeloid leukemia, $C M L$ chronic myeloid leukemia, $C M V$ cytomegalovirus, $G v H D$ graft-versus-host disease, $H L A$ human leucocyte antigens, $M D S$ myelodysplastic syndrome 


\section{Dermoscopic Procedure}

Dermoscopy was performed by a certified dermatologist who is an expert in dermoscopy and an integral member of the transplantation team. Dermoscopic assessment of skin lesions was performed using the polarized DermLite FOTO dermoscope (3Gen, LLC, San Juan Capistrano, CA, USA) at tenfold magnification. All dermoscopic images were captured and saved using the DermLite Cam digital dermoscopy camera (3Gen, LLC) with polarized light and then independently analyzed by two certified dermoscopists (GK-W and IZ), who were blinded to the histopathologic reports, in accordance with the methods of the study. The selection of dermoscopic features included in the evaluation process was based on our preliminary observations and data available in the literature [6, 10-13].

The type of background and vessels, presence of hyperpigmentation and scaling were taken into account in the final dermoscopic description. The following dermoscopic criteria were evaluated: (1) the presence of pigmentation; (2) pigmentation arrangement: uniform, patchy or rhomboidal; (3) the presence of granularity; (4) the presence of scaling (mild, moderate, severe); (5) type of blood vessels: linear, dotted, polymorphic or the presence of erythema; (5) arrangement of blood vessels and erythema as unspecific or clustered; (6) the presence of white patchy areas.

\section{Statistical Analysis}

The Kruskal-Wallis or Mann-Whitney $U$ oneway analysis of variance test was used with nonnormal distribution of data to assess the differentiation of quantitative variables in independent groups (defined by type or grade of GvHD), and the Fisher exact test was used to assess the diversity of the studied signs depending on group (e.g. type/grade of GvHD). Values of Cohen's Kappa $(\kappa)$ with 95\% confidence intervals (CIs) were calculated to assess agreement between histopathology, dermoscopy and clinical signs; these were evaluated separately for all and for only chronic cases of GvHD in order to exclude potential confounders. Given the different levels of scores between the histopathology, dermoscopy and clinical evaluation, for this stage of analysis all variables were recoded as a binomial variable (absence or presence). $\kappa$ values were interpreted using the widely accepted criteria proposed by Landis and Koch: poor agreement $<0.20$; fair $0.21-0.40$; moderate $0.41-0.60$; good $0.61-0.80$; very good 0.81-1.00 [14]. Multivariate analyses could not be conducted due to the small sample size. All analyses were performed using procedures available in R 3.2.5 software (R Core Team, Vienna, Austria) [15]. The level of significance was set at $p<0.05$.

\section{Complaince with Ethics Guidelines}

Authors have received approval from local ethics committee of Maria Sklodowska-Curie National Research Institute of Oncology (MSCNRIO), Gliwice Branch (reference number $\mathrm{KB} / 430-41 / 13)$. The study was study conducted in accordance with the Helsinki Declaration of 1964, and its later amendments. All subjects provided informed consent to participate in the study as well as for publication.

\section{RESULTS}

\section{Basic Characteristics with Descriptive Statistics}

Graft-versus-host disease was confirmed by histopathology in 19 of the 20 allo-HSCT recipients. Four patients developed symptoms of AGvHD ( 2 patients with clinical overall grade I and skin score 1 and 2, respectively; 1 with grade II, skin score 3 ; and 1 with grade III, skin score 1 with gut score 2 ) without subsequently developing CGvHD; these patients were all evaluated as grade 2 on the modified Lerner's scale. Five patients were previously diagnosed with AGvHD followed by CGvHD, and in ten patients cGvHD occurred without preceding AGvHD. All 15 cases of CGvHD were classified as "likely" in the histopathologic report [8]. The overall grading according to the NIH guidelines 
was as follows: mild cGvHD with skin score 1 $(n=7)$, moderate with skin score $2(n=5)$ and severe cGvHD with skin score $3(n=3)$. Time to onset of GvHD after the allo-HSCT procedure for all $(n=19)$ patients ranged from 22 to 1452 (median 259, interquartile range [IQR] 143.5496.5) days. Median onset for CGvHD and AGvHD was 262 (IQR 173-573.5) and 22 (IQR 29.5-106.2) days, respectively.

Among all patients with both types of GvHD the most frequent clinical features were classic poikiloderma ( $n=12 ; 63.2 \%)$ (Fig. $1 \mathrm{a}, \mathrm{d}, \mathrm{g})$ and "other" features, including fine flakes scaling $(n=10 ; 52.6 \%)$ and perifollicular papules ( $n=6 ; 31.6 \%)$. Maculopapular rash was present in all four cases of AGvHD and absent in all cases of CGvHD $(p<0.001)$. Classic poikiloderma and "other" features, including fine flakes scaling and perifollicular papules, were present in the majority of cGvHD cases (12 of $15,80 \% ; 10$ of $15,66.7 \%, 6$ of $15,40 \%$, respectively), while absent in all AGvHD cases ( $p=0.009 ; p=0.03 ; p=0.3$, respectively). Statistically significant differences in occurrence of maculopapular rash and other fine flakes scaling were found to relate to grade of GvHD $(p=0.04)$. The complete set of data is shown in Table 2.

In our patient group, the most frequent dermoscopic signs, irrespective of the GvHD type (chronic vs. acute) and its grade, were type of vessels and scaling (each $n=14,73.7 \%$ ). Hyperpigmentation (Fig. 1b, e, h) and white patchy areas (Fig. 1b, e) were present in eight patients $(42.1 \%)$. More detailed results are shown in Table 2 . The most common histopathologic characteristics (regardless of the type of GvHD) were hyperkeratosis (17/19, $89.5 \%)$ and lymphocytic infiltration (15/19, 78.9\%) (Fig. 1c, f, i). Our data have confirmed that collagen bundles (Fig. 1c) and melanophages (Fig. 1c, f, i) were significantly more frequently identified among patients with CGvHD (10/15; 66.7\%, $p=0.03$ and 11/15; $73.3 \%, p=0.02$, respectively), while presence of satellitosis may be one of the factors associated with grading of GvHD ( $p=0.03)$. All results are shown in Table 2.
Fig. 1 a-c Patient 1 (41-year-old male patient, 633 days after allogeneic hematopoietic stem cell transplantation [allo-HSCT]). a Clinical picture of chronic cutaneous graft-versus-host-disease (CGvHD): extensive sclerotic changes, including both sclerodermoid-like and morphealike features with poikiloderma on the trunk and extremities. b Dermoscopy shows the presence of granularity, rhomboidal pigment arrangement, white patchy areas and mild scaling. c Histopathology of the skin biopsy with homogenization of the papillary and reticular dermis, few vacuolar changes in the dermal-epidermal junction, dispersed melanophages in the reticular dermis, lack of rete ridges, deep reticular collagen bundles and minimal hyperkeratosis (original magnification $\times 10$ ). $\mathbf{d}-\mathbf{f}$ Patient 2 (32-year-old male patient, 188 days after allo-HSCT). d Clinical picture of CGvHD: classic poikiloderma with fine flake scaling on the trunk. e Dermoscopy reveals the presence of granularity, rhomboidal pigment arrangement, white patchy areas and moderate scaling. f Skin biopsy shows homogenization (sclerosis) of most of the papillary dermis, some vacuolar changes of basilar keratinocytes, melanophages in the papillary dermis, very sparse lymphocytic infiltrate and hyperkeratosis (original magnification $\times 20$ ). g-i Patient 3 (27-year-old female patient, 262 days after allo-HSCT). g Clinical picture of CGvHD: slight poikiloderma with multiple, hyperpigmented focal lesions on the trunk. $\mathbf{h}$ Dermoscopy indicated the presence of very slight granularity and mild scaling. i Histopathologic features of the skin biopsy: mild vacuolar changes in the dermal-epidermal border, sparse lymphocytic infiltrate in the papillary and reticular dermis, mostly perivascular, melanophages in the reticular dermis, collagen bundles in the deep reticular dermis, and hyperkeratosis (original magnification $\times 20$ )

\section{Concordance Between Different Methods}

Concordance was assessed separately for all cases of AGvHD and CGvHD. To maintain the clarity and brevity of the results, we present only data for chronic cases.

\section{Agreement Between Dermoscopy and Clinical Signs}

Classic poikiloderma was associated positively with pigmentation $(\kappa=0.36 ; 95 \%$ CI $0.01-0.71$ ) and possibly with granularity $(\kappa=0.29 ; 95 \% \mathrm{CI}$ -0.02 to 0.6). Classic sclerotic features were positively associated with white patchy areas 

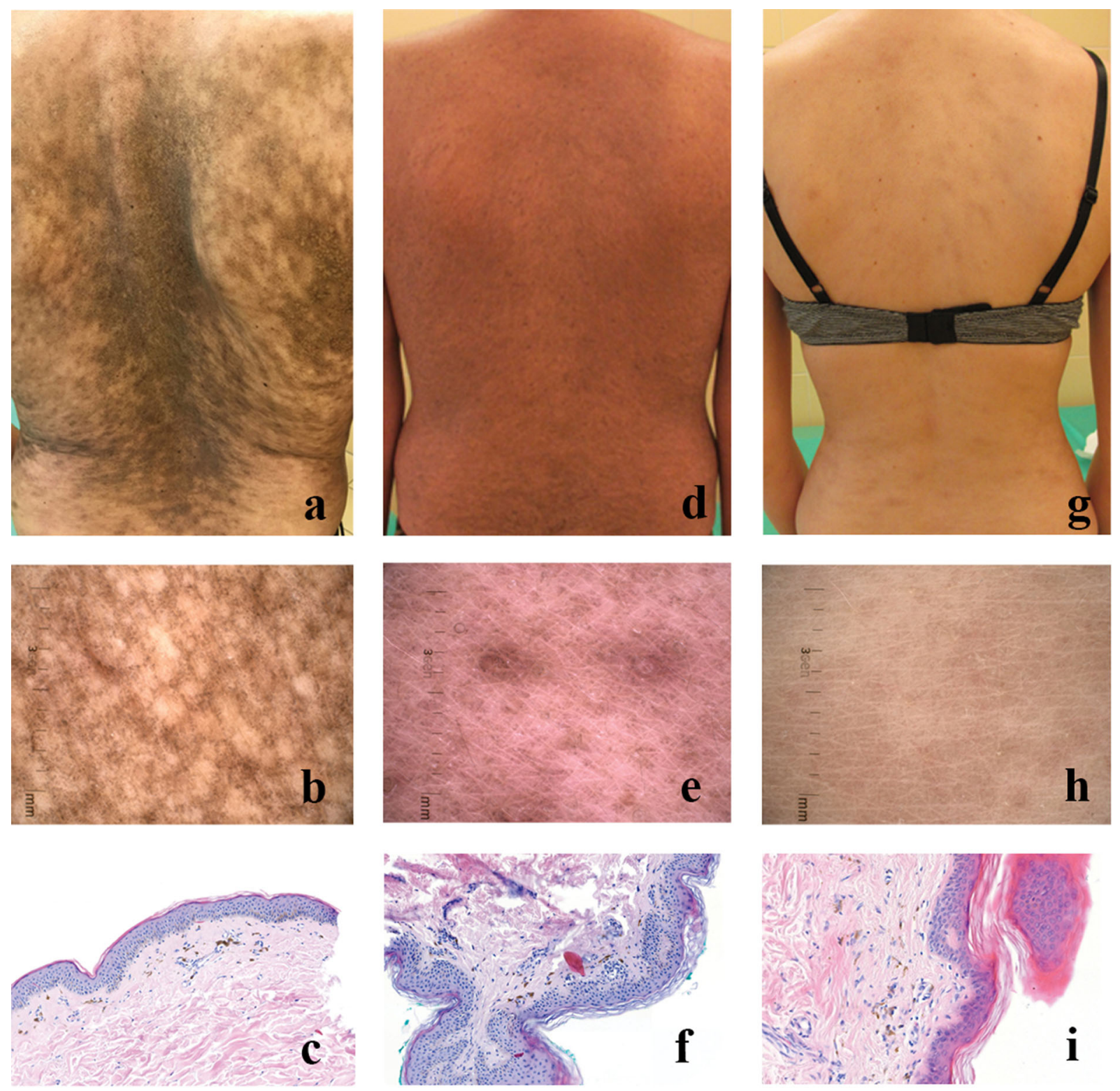

and pigmentation (both $\kappa=0.44 ; 95 \%$ CI 0.06-0.83) (Fig. 2a-f). The presence of dermoscopic features within the skin lesions accompanied by classic lichen planus-like mucosa could be surrogate of pigmentation $(\kappa=0.44$; 95\% CI 0.06-0.83) and granularity $(\kappa=0.55$; 95\% CI 0.14-0.96). "Other" features, such as other perifollicular papule and fine flakes scaling, might be linked with the presence of scaling in dermoscopy $(\kappa=-0.43 ; 95 \%$ CI -0.86 to $0, \kappa=0.33 ; 95 \%$ CI -0.17 to 0.83 , respectively). The complete results for this analysis are presented in Table 3.

\section{Agreement Between Dermoscopy and Histopathology}

The histopathic examination found that lymphocytic infiltrations were less prevalent when dermoscopy revealed white patchy areas $(\kappa=-0.55$; $95 \%$ CI -0.96 to -0.15$)$. Agreement was fair between the occurrence of 
melanophages in the skin sample and dermoscopic granularity ( $\kappa=0.39,95 \%$ CI $0.04-0.74)$; in comparison, the histopathic findings of scaling and vessels were more scarce $(\kappa=-0.3$, $95 \%$ CI -0.52 to $-0.07 ; \kappa=-0.42,95 \%$ CI -0.68 to -0.16 ; respectively). The presence of vacuolar changes at the dermal-epidermal junction in the skin samples was inversely linked with scaling in the dermoscopic evaluation $(\kappa=-0.33 ; 95 \% \mathrm{CI}-0.6$ to -0.07$)$. There was a trend for an association between the pathological sign of collagen bundles and dermoscopic findings of white patchy areas or scaling features $(\kappa=0.35,95 \% \mathrm{CI}-0.08$ to $0.78 ; \kappa=0.33,95 \% \mathrm{CI}-0.17$ to 0.83 ; respectively). The complete results for this analysis are given in Table 3.

\section{Agreement Between Dermoscopic Signs}

We found an agreement between co-presence of pigmentation with: white patchy areas $(\kappa=0.73 ; 95 \%$ CI $0.39-1)$, granularity $(\kappa=0.59$; 95\% CI 0.19-1), while negative for vessels $(\kappa=-0.43 ; 95 \%$ CI -0.87 to -0.001$)$. Presence of granularity feature was associated with absence of vessels $(\kappa=-0.75 ; 95 \% \mathrm{CI}-1$ to $-0.3)$. The complete results from this analysis are given in Table 3.

\section{Possible Determinants of Early or Late Onset of GvHD}

The presence of a number of dermoscopic signs at the time of diagnosis may determine the onset of GvHD, but the results of our analysis (Mann-Whitney $U$ test) were not statistically significant. For example, patients with presence of pigmentation may be more likely to have later onset of GvHD than those without (median time in days 351.0 [IQR 180.2-682.2] vs. 259.0 [IQR 119.0-299.5], respectively; $p=0.3$ ); similarly with the occurrence of scaling (267.5 [IQR 196.8-603.2] vs. 157.0 [IQR 130.0-158.0]; $p=0.1)$ or granularity (370.5 [IQR 206.5-594.5] vs. 223.0 [IQR 108.0-326.0]; $p=0.3$ ).

Earlier occurrence of GvHD was associated with the presence of vacuolar changes in the histopathologic examination (median time in days: 173.0 [IQR 113.5-270.2] vs. 514.0 [IQR
479.0-654.0]; $p=0.03$ ), satellitosis (70.5 [IQR 32.8-120.2] vs. 273.0 [IQR 205.5-573.5]; $p=0.009$ ) and (only a trend) apoptosis (33.0 [IQR 32.5-128.0] vs. 267.5 [IQR 157.8-543.8]; $p=0.08$ ). Later occurrence of GvHD was associated with histopathologic signs of subepidermal homogenization (479.0 [IQR 259.0-654.0] vs. 143.5 [IQR 51.8-243.5]; $p=0.008$ ), collagen bundles (496.5 [IQR 259.8-648.8] vs. 157.0 [IQR 33.0-223.0]; $p=0.006$ ) and (statistically not significantly) with presence of macrophages with pigment (273.0 [IQR 173.0-573.5] vs. 165.5 [IQR 32.8-275.8]; $p=0.1$ ).

Among the clinical signs, maculo-papular rash turned out to be typical for early GvHD (32.5 [IQR 29.5-106.2] vs. 262.0 [IQR 173.0-573.5]; $p=0.04$ ), while for late GvHD it was classic sclerotic features sign $(830.0$ [IQR 731.5-1141.0] vs. 205.5 [IQR 124.5-286.2]; $p=0.004)$. The clinical cutaneous sign classic lichen planus-like was excluded from the analysis as it was absent in all cases.

\section{DISCUSSION}

Dermoscopic assessment in transplantation medicine has been limited to specific casuistic cases, including dermoscopic follow-up in a patient who underwent a near-full facial transplant [16]. The first report by Kaminska-Winciorek et al. [6] implied that dermoscopy might be used as a non-invasive diagnostic and monitoring tool for AGvHD of the skin in allo-HSCT patients. In that study, dermoscopy revealed a pinkish or reddish background with well-visible, marked, multiple, thin telangiectasias in allo-HSCT patients with AGvHD of the skin [6]. Moreover, in different studies on patients after allo-HSCT, changes in nail plates (onychoscopy) [17] and cicatrical alopecia in trichoscopy [18] were described, and changes in melanocytic lesions were monitored [19].

The diagnosis of acute and chronic GvHD is currently based on clinical criteria, supplemented in selected cases by histopathologic examination of the skin biopsy. Allo-HSCT patients are very often in a severely poor general condition, with impaired immune function that is not uncommonly accompanied by 
Table 2 Frequency of clinical, dermoscopic and histopathologic signs according to grade and type of graft-versus-host disease

\begin{tabular}{|c|c|c|c|c|c|c|c|c|c|}
\hline \multirow[t]{2}{*}{ Signs of GvHD } & \multicolumn{3}{|c|}{ Type of GvHD, $n$ (\%) } & \multirow[t]{2}{*}{$p^{\mathrm{a}}$} & \multicolumn{4}{|c|}{ Grade(G) of GvHD, $n(\%)$} & \multirow[t]{2}{*}{$p^{\mathrm{a}}$} \\
\hline & $\begin{array}{l}\text { Total } \\
(n=19)\end{array}$ & $\begin{array}{l}\text { Acute } \\
(n=4)\end{array}$ & $\begin{array}{l}\text { Chronic } \\
(n=15)\end{array}$ & & $\begin{array}{l}\text { G0 } \\
(n=10)\end{array}$ & $\begin{array}{l}\text { G I } \\
(n=5)\end{array}$ & $\begin{array}{l}\text { G II } \\
(n=2)\end{array}$ & $\begin{array}{l}\text { G III } \\
(n=2)\end{array}$ & \\
\hline
\end{tabular}

Clinical

Maculopapular rash acute GvHD

\begin{tabular}{|c|c|c|c|c|c|c|c|c|}
\hline No & $15(78.9)$ & $0(0)$ & $15(100)$ & $<0.001$ & $10(100)$ & $3(60)$ & $1(50)$ & $1(50)$ \\
\hline Yes & $4(21.1)$ & $4(100)$ & $0(0)$ & & $0(0)$ & $2(40)$ & $1(50)$ & $1(50)$ \\
\hline
\end{tabular}

Classic poikiloderma

$\begin{array}{lrlrllllll}\text { No } & 7(36.8) & 4(100) & 3(20) & 0.009 & 2(20) & 3(60) & 1(50) & 1(50) & 0.4 \\ \text { Yes } & 12(63.2) & 0(0) & 12(80) & & 8(80) & 2(40) & 1(50) & 1(50)\end{array}$

Classic sclerotic features

$\begin{array}{lcllllllll}\text { No } & 16(84.2) & 4(100) & 12(80) & 1 & 8(80) & 4(80) & 2(100) & 2(100) & 1 \\ \text { Yes } & 3(15.8) & 0(0) & 3(20) & & 2(20) & 1(20) & 0(0) & 0(0)\end{array}$

Classic lichen planus-like of mucosa

$\begin{array}{lrllllllll}\text { No } & 16(84.2) & 4(100) & 12(80) & 1 & 8(80) & 5(100) & 2(100) & 1(50) & 0.3 \\ \text { Yes } & 3(15.8) & 0(0) & 3(20) & & 2(20) & 0(0) & 0(0) & 1(50)\end{array}$

Other features

$\begin{array}{lrllllllll}\text { No } & 5(26.3) & 4(100) & 1(6.7) & 0.001 & 0(0) & 3(60) & 1(50) & 1(50) & 0.01 \\ \text { Yes } & 14(73.7) & 0(0) & 14(93.3) & & 10(100) & 2(40) & 1(50) & 1(50)\end{array}$

Other perifolicular papule

(keratosis pilaris)

$\begin{array}{lrllllllll}\text { No } & 13(68.4) & 4(100) & 9(60) & 0.3 & 6(60) & 4(80) & 2(100) & 1(50) & 0.7 \\ \text { Yes } & 6(31.6) & 0(0) & 6(40) & & 4(40) & 1(20) & 0(0) & 1(50) & \\ \begin{array}{l}\text { Other fine flake scaling } \\ \text { (ichthyosis) }\end{array} & & & & & & & & & \\ \text { No } & 9(47.4) & 4(100) & 5(33.3) & 0.03 & 2(20) & 4(80) & 1(50) & 2(100) & 0.04 \\ \text { Yes } & 10(52.6) & 0(0) & 10(66.7) & & 8(80) & 1(20) & 1(50) & 0(0) & \end{array}$

Dermoscopy

Pigmentation

\begin{tabular}{lrllllllll} 
No & $11(57.9)$ & $3(75)$ & $8(53.3)$ & 0.6 & $6(60)$ & $4(80)$ & $0(0)$ & $1(50)$ & 0.4 \\
Yes & $8(42.1)$ & $1(25)$ & $7(46.7)$ & & $4(40)$ & $1(20)$ & $2(100)$ & $1(50)$ & \\
Pigment arrangement & & & & & & & & & \\
\hline
\end{tabular}


Table 2 continued

\begin{tabular}{|c|c|c|c|c|c|c|c|c|c|}
\hline \multirow[t]{2}{*}{ Signs of GvHD } & \multicolumn{3}{|c|}{ Type of GvHD, $n$ (\%) } & \multirow[t]{2}{*}{$p^{a}$} & \multicolumn{4}{|c|}{ Grade(G) of GvHD, $n$ (\%) } & \multirow[t]{2}{*}{$p^{\mathrm{a}}$} \\
\hline & $\begin{array}{l}\text { Total } \\
(n=19)\end{array}$ & $\begin{array}{l}\text { Acute } \\
(n=4)\end{array}$ & $\begin{array}{l}\text { Chronic } \\
(n=15)\end{array}$ & & $\begin{array}{l}\text { G0 } \\
(n=10)\end{array}$ & $\begin{array}{l}\text { G I } \\
(n=5)\end{array}$ & $\begin{array}{l}\text { G II } \\
(n=2)\end{array}$ & $\begin{array}{l}\text { G III } \\
(n=2)\end{array}$ & \\
\hline None & $11(57.9)$ & $3(75)$ & $8(53.3)$ & 0.2 & $6(60)$ & $4(80)$ & $0(0)$ & $1(50)$ & 0.1 \\
\hline Uniform/patchy & $2(10.5)$ & $1(25)$ & $1(6.7)$ & & $0(0)$ & $1(20)$ & $1(50)$ & $0(0)$ & \\
\hline Rhomboidal & $6(31.6)$ & $0(0)$ & $6(40)$ & & $4(40)$ & $0(0)$ & $1(50)$ & $1(50)$ & \\
\hline \multicolumn{10}{|l|}{ Granularity } \\
\hline No & $13(68.4)$ & $4(100)$ & $9(60)$ & 0.3 & $6(60)$ & $5(100)$ & $1(50)$ & $1(50)$ & 0.3 \\
\hline Yes & $6(31.6)$ & $0(0)$ & $6(40)$ & & $4(40)$ & $0(0)$ & $1(50)$ & $1(50)$ & \\
\hline \multicolumn{10}{|l|}{ Scaling } \\
\hline No & $5(26.3)$ & $2(50)$ & $3(20)$ & 0.3 & $2(20)$ & $2(40)$ & $0(0)$ & $1(50)$ & 0.6 \\
\hline Yes & $14(73.7)$ & $2(50)$ & $12(80)$ & & $8(80)$ & $3(60)$ & $2(100)$ & $1(50)$ & \\
\hline \multicolumn{10}{|l|}{ Type of vessels } \\
\hline Dotted & $2(10.5)$ & $1(25)$ & $1(6.7)$ & 0.6 & $1(10)$ & $1(20)$ & $0(0)$ & $0(0)$ & 0.6 \\
\hline Linear & $10(52.6)$ & $3(75)$ & $7(46.7)$ & & $6(60)$ & $2(40)$ & $1(50)$ & $1(50)$ & \\
\hline Polymorphic & $1(5.3)$ & $0(0)$ & $1(6.7)$ & & $0(0)$ & $1(20)$ & $0(0)$ & $0(0)$ & \\
\hline Erythema & $1(5.3)$ & $0(0)$ & $1(6.7)$ & & $0(0)$ & $1(20)$ & $0(0)$ & $0(0)$ & \\
\hline None & $5(26.3)$ & $0(0)$ & $5(33.3)$ & & $3(30)$ & $0(0)$ & $1(50)$ & $1(50)$ & \\
\hline \multicolumn{10}{|c|}{ Erythema arrangement } \\
\hline Patchy & $12(63.2)$ & $4(100)$ & $8(53.3)$ & 0.5 & $5(50)$ & $5(100)$ & $1(50)$ & $1(50)$ & 0.5 \\
\hline Non-specific & $2(10.5)$ & $0(0)$ & $2(13.3)$ & & $2(20)$ & $0(0)$ & $0(0)$ & $0(0)$ & \\
\hline None & $5(26.3)$ & $0(0)$ & $5(33.3)$ & & $3(30)$ & $0(0)$ & $1(50)$ & $1(50)$ & \\
\hline \multicolumn{10}{|l|}{ White patchy areas } \\
\hline No & $11(57.9)$ & $3(75)$ & $8(53.3)$ & 0.6 & $5(50)$ & $3(60)$ & $1(50)$ & $2(100)$ & 0.9 \\
\hline Yes & $8(42.1)$ & $1(25)$ & $7(46.7)$ & & $5(50)$ & $2(40)$ & $1(50)$ & $0(0)$ & \\
\hline \multicolumn{10}{|l|}{ Histopathology } \\
\hline \multicolumn{10}{|l|}{ Apoptosis } \\
\hline No & $16(84.2)$ & $2(50)$ & $14(93.3)$ & 0.1 & $9(90)$ & $5(100)$ & $1(50)$ & $1(50)$ & 0.1 \\
\hline Yes & $3(15.8)$ & $2(50)$ & $1(6.7)$ & & $1(10)$ & $0(0)$ & $1(50)$ & $1(50)$ & \\
\hline \multicolumn{10}{|l|}{ Vacuolar changes } \\
\hline No & $5(26.3)$ & $0(0)$ & $5(33.3)$ & 0.5 & $4(40)$ & $1(20)$ & $0(0)$ & $0(0)$ & 0.7 \\
\hline Yes & $14(73.7)$ & $4(100)$ & $10(66.7)$ & & $6(60)$ & $4(80)$ & $2(100)$ & $2(100)$ & \\
\hline Satellitosis & & & & & & & & & \\
\hline
\end{tabular}


Table 2 continued

\begin{tabular}{|c|c|c|c|c|c|c|c|c|c|}
\hline \multirow[t]{2}{*}{ Signs of GvHD } & \multicolumn{3}{|c|}{ Type of GvHD, $n$ (\%) } & \multirow[t]{2}{*}{$p^{a}$} & \multicolumn{4}{|c|}{ Grade(G) of GvHD, $n$ (\%) } & \multirow[t]{2}{*}{$p^{\mathrm{a}}$} \\
\hline & $\begin{array}{l}\text { Total } \\
(n=19)\end{array}$ & $\begin{array}{l}\text { Acute } \\
(n=4)\end{array}$ & $\begin{array}{l}\text { Chronic } \\
(n=15)\end{array}$ & & $\begin{array}{l}\text { G0 } \\
(n=10)\end{array}$ & $\begin{array}{l}\text { G I } \\
(n=5)\end{array}$ & $\begin{array}{l}\text { G II } \\
(n=2)\end{array}$ & $\begin{array}{l}\text { G III } \\
(n=2)\end{array}$ & \\
\hline No & $15(78.9)$ & $2(50)$ & $13(86.7)$ & 0.2 & $9(90)$ & $5(100)$ & $1(50)$ & $0(0)$ & 0.03 \\
\hline Yes & $4(21.1)$ & $2(50)$ & $2(13.3)$ & & $1(10)$ & $0(0)$ & $1(50)$ & $2(100)$ & \\
\hline \multicolumn{10}{|l|}{ Hyperkeratosis } \\
\hline No & $2(10.5)$ & $1(25)$ & $1(6.7)$ & 0.4 & $1(10)$ & $1(20)$ & $0(0)$ & $0(0)$ & 1 \\
\hline Yes & $17(89.5)$ & $3(75)$ & $14(93.3)$ & & $9(90)$ & $4(80)$ & $2(100)$ & $2(100)$ & \\
\hline \multicolumn{10}{|l|}{$\begin{array}{l}\text { Subepidermal } \\
\text { homogenization }\end{array}$} \\
\hline No & $10(52.6)$ & $4(100)$ & $6(40)$ & 0.09 & $3(30)$ & $3(60)$ & $2(100)$ & $2(100)$ & 0.1 \\
\hline Yes & $9(47.4)$ & $0(0)$ & $9(60)$ & & $7(70)$ & $2(40)$ & $0(0)$ & $0(0)$ & \\
\hline \multicolumn{10}{|l|}{ Collagen bundles } \\
\hline No & $9(47.4)$ & $4(100)$ & $5(33.3)$ & 0.03 & $3(30)$ & $3(60)$ & $1(50)$ & $2(100)$ & 0.4 \\
\hline Yes & $10(52.6)$ & $0(0)$ & $10(66.7)$ & & $7(70)$ & $2(40)$ & $1(50)$ & $0(0)$ & \\
\hline \multicolumn{10}{|c|}{$\begin{array}{l}\text { Macrophages with } \\
\text { pigment (melanophages) }\end{array}$} \\
\hline No & $8(42.1)$ & $4(100)$ & $4(26.7)$ & 0.02 & $3(30)$ & $3(60)$ & $1(50)$ & $1(50)$ & 0.7 \\
\hline Yes & $11(57.9)$ & $0(0)$ & $11(73.3)$ & & $7(70)$ & $2(40)$ & $1(50)$ & $1(50)$ & \\
\hline \multicolumn{10}{|c|}{ Lymphocytic infiltration } \\
\hline No & $4(21.1)$ & $0(0)$ & $4(26.7)$ & 0.5 & $3(30)$ & $1(20)$ & $0(0)$ & $0(0)$ & 1 \\
\hline Yes & $15(78.9)$ & $4(100)$ & $11(73.3)$ & & $7(70)$ & $4(80)$ & $2(100)$ & $2(100)$ & \\
\hline \multicolumn{10}{|c|}{ Skin(epidermal) thinning } \\
\hline No & $14(73.7)$ & $2(50)$ & $12(80)$ & 0.3 & $7(70)$ & $4(80)$ & $1(50)$ & $2(100)$ & 1 \\
\hline Yes & $5(26.3)$ & $2(50)$ & $3(20)$ & & $3(30)$ & $1(20)$ & $1(50)$ & $0(0)$ & \\
\hline
\end{tabular}

Values in table are the frequency, presented as a number (of patients) with the percentage in parenthesis

a Significance based on the Fisher's exact test

thrombocytopenia and increased risk of infection. Therefore, rapid diagnosis when the first GvHD symptoms occur offers the opportunity to start early treatment, reduce mortality and decrease the risk of developing chronic GvHD of the skin. In this context, additional options for a rapid, non-invasive diagnosis of this condition are being sought. Our study is the second attempt to identify correlations between the clinical, dermoscopic and histopathologic features of GvHD.

The key dermoscopic findings we found to correlate with histopathologic features were granularity, scaling, white patches and the presence of linear vessels.

Chronic GvHD has a multi-organ manifestation, resembling the clinical picture of connective tissue diseases [5]. Due to complex disease pathomechanisms and manifestations, 

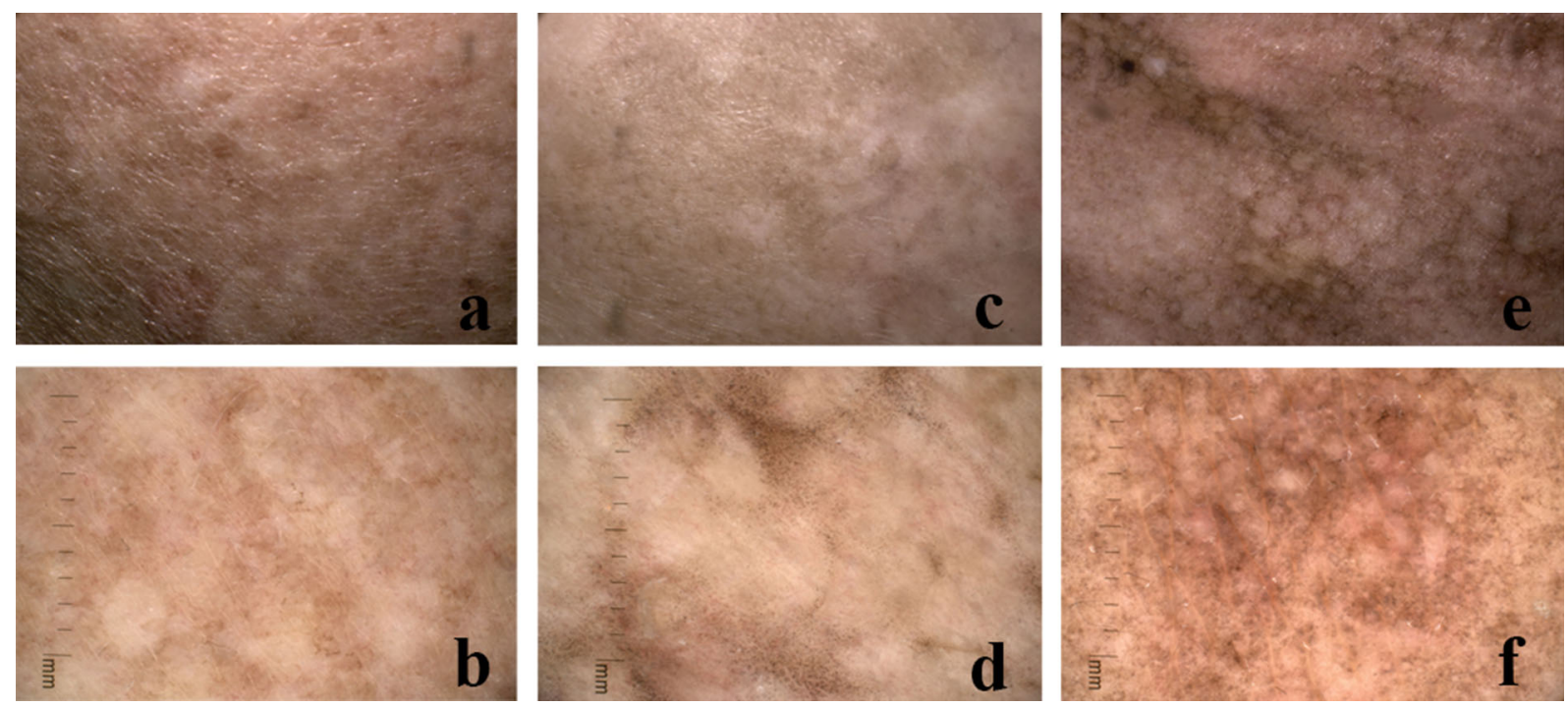

Fig. 2 Clinical (a, c, e) and dermoscopic (b, d, f) images of CGvHD in three different patients (a, b; c, d; e, f). b Patchy pigment arrangement, $\mathbf{d}$, f rhomboidal pigment arrangement with numerous gray-brown dots defined as granularities, b, d, f white patchy areas. The dermoscopic

new NIH criteria have been developed for diagnostics and therapy monitoring $[5,7,8,20-22]$. In the majority of cases, especially those that raise clinical doubts or require confirmed diagnosis, skin biopsies are taken for histopathologic assessment. Validated histologic changes help the clinician to make the differential diagnosis of cGvHD-including apoptosis within the basal or lower spinosum layers of the epidermis, vacuolar changes and apoptotic keratinocytes. Archetypical, but not pathognomonic features of both acute and chronic GvHD include superficial interface dermatitis with vacuolar change predominantly in the basal layer or a lichenoid pattern of lymphocytic inflammation with or without lymphocyte satellitosis [7].

In our study, we found a fair agreement between the occurrence of melanophages in the skin sample and the dermoscopic sign of granularity, which represents dermal pigmentary incontinence resulting from a lichenoid inflammation and damage to the dermal-epidermal interface $[7,23]$. Our study also demonstrated that collagen bundles and melanophages were identified significantly more images are almost identical (DermLite Cam digital dermoscopy camera, polarized light, $\times 10$ magnification)

frequently among patients with CGvHD. In histopathologic terms, granularity, which refers to the occurrence of multiple blue-gray dots (peppering), has been associated with the presence of melanophages. In the study conducted by Barreiro-Capurro et al. [19], a blue-gray regression was present in $93.8 \%$ of the lesions with $\geq 3$ points in the 7 -point checklist, probably resulting from fibroplasia and abundant melanophages [23]. The presence of granularity, at the periphery, irregularly distributed or in association with a red and white color, has been found to be statistically highly significant for the diagnosis of melanoma [24]. It should be highlighted, however, that the presence of granularity in GvHD cases is probably analogous to that observed in lichen planus $[25,26]$ or lichen planus-like keratoses (LPLK) [27]. Güngör et al. [26] studied 170 cutaneous lichen planus lesions and observed pigment patterns in $11 \%$ of these. These authors categorized the lesions into three subgroups: peripheral dots/globules; peripheral homogeneous cloudlike pigment pattern; and reticular pigment pattern [26]. Both pigmented lichen planus and ashy dermatosis are characterized by peppering 
Table 3 Level of agreement between the presence of selected dermoscopic signs and clinical signs, pathologic signs and "other" dermoscopic signs as assessed with values of Cohen's Kappa statistics and their 95\% confidence intervals

\section{Clinical signs, pathologic signs and}

"other" dermoscopic signs

\section{Selected dermoscopic signs}

\begin{tabular}{lllll}
\hline Pigmentation & Granularity & Scaling & Vessels & $\begin{array}{l}\text { White } \\
\text { patchy areas }\end{array}$
\end{tabular}

\section{Clinical signs}

Maculopapular rash acute gvhd

$\begin{array}{clllll}\kappa & 0 & 0 & 0 & 0 & 0 \\ 95 \% \mathrm{CI} & (0-0) & (0-0) & (0-0) & (0-0) & (0-0)\end{array}$

Classic poikiloderma

$$
\kappa
$$

$95 \% \mathrm{CI}$

Classic lichen planus-like$$
\kappa
$$

$95 \% \mathrm{CI}$

Classic sclerotic features

$\kappa$
$95 \% \mathrm{CI}$

Classic lichen planus-like of mucosa

$$
\begin{gathered}
\kappa \\
95 \% \mathrm{CI}
\end{gathered}
$$

Other features

$\kappa$
$95 \% \mathrm{CI}$

Other perifollicular papule (keratosis pilaris)

$$
\kappa
$$

95\% CI

Other fine flakes scaling (ichthyosis)

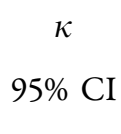

$$
\begin{array}{lllcc}
\mathbf{0 . 3 6} & 0.29 & 0.17 & \mathbf{- 0 . 3 3} & 0.1 \\
(\mathbf{0 . 0 1 - 0 . 7 1 )} & (-0.02 \text { to } & (-0.4 \text { to } & \mathbf{( - \mathbf { 0 . 6 } \text { to }} & (-0.28 \text { to } \\
& 0.6) & 0.73) & \mathbf{- 0 . 0 7 )} & 0.48)
\end{array}
$$

$\begin{array}{lllll}0 & 0 & 0 & 0 & 0 \\ (0-0) & (0-0) & (0-0) & (0-0) & (0-0)\end{array}$

$$
\begin{array}{llll}
\mathbf{0 . 4 4} & 0.24 & 0.12 & 0 \\
(\mathbf{0 . 0 6}-\mathbf{0 . 8 3}) & (-0.22 \text { to } & (-0.05 \text { to } & (-0.32 \text { to } \\
& 0.7) & 0.29) & 0.32)
\end{array}
$$$$
0.44
$$

$\begin{array}{llccc}\mathbf{0 . 4 4} & \mathbf{0 . 5 5} & -0.08 & -0.22 & 0.17 \\ (\mathbf{0 . 0 6}-\mathbf{0 . 8 3}) & (\mathbf{0 . 1 4 - 0 . 9 6 )} & (-0.36 \text { to } & (-0.61 \text { to } & (-0.25 \text { to } \\ & & 0.2) & 0.16) & 0.59)\end{array}$

0.09

$(-0.09$ to

0.27 )

$-0.11$

$-0.13$

$-0.13$

$(-0.39$ to

$0.12)$

$(-0.29$ to

$0.06)$

$(-0.34$ to

$0.09)$

$0.12)$

$$
-0.22
$$$$
(-0.7 \text { to }
$$$$
0.27)
$$

$$
-0.11
$$$$
(-0.61 \text { to }
$$$$
0.39)
$$$$
-0.43
$$

0

$-0.22$

$(-0.86$ to
$-0.001)$

$(-0.44$ to

0.44 )

$$
0.27)
$$
0
0.33
$(-0.44$ to $\quad(-0.17$ to 0.83 )

0.1

0.09

$(-0.41$ to $(-0.38$ to $0.55)$ 
Table 3 continued

Clinical signs, pathologic signs and

“other” dermoscopic signs

Selected dermoscopic signs

\begin{tabular}{llll}
\hline Pigmentation Granularity & Scaling & Vessels
\end{tabular}

patchy areas

\section{Histopathology}

Apoptosis

$\kappa$

$95 \% \mathrm{CI}$

Vacuolar changes

$\kappa$
$95 \% \mathrm{CI}$

Satelitosis

$\kappa$
$95 \% \mathrm{CI}$

Hyperkeratosis

$\kappa$
$95 \% \mathrm{CI}$

Subepidermal homogenisation

$$
\kappa
$$

$95 \% \mathrm{CI}$

Collagen bundles

$$
\kappa
$$

$95 \% \mathrm{CI}$

$$
\begin{array}{lr}
0.09 & 0.25 \\
(-0.38 \text { to } & (-0.16 \\
0.55) & 0.66)
\end{array}
$$$$
-0.15
$$$$
0.24
$$$$
(-0.62 \text { to }
$$$$
0.32 \text { ) }
$$

$(-0.22$ to

0.7 )

0.29

$(-0.21$ to

0.78 )

$-0.17$

(- 0.64 to

-0.13 to

0.43 ) 
Table 3 continued

\begin{tabular}{lccccc}
\hline $\begin{array}{l}\text { Clinical signs, pathologic signs and } \\
\text { "other" dermoscopic signs }\end{array}$ & \multicolumn{4}{l}{ Selected dermoscopic signs } \\
\cline { 2 - 6 } & Pigmentation & Granularity & Scaling & Vessels & $\begin{array}{c}\text { White } \\
\text { patchy areas }\end{array}$ \\
\hline $95 \%$ CI & $(-0.72$ to & $(-0.51$ to & $(-0.45$ to & $(-0.31$ to & $\begin{array}{c}(-\mathbf{0 . 9 6} \text { to } \\
\end{array}$ \\
$0.14)$ & $0.31)$ & $0.6)$ & $0.73)$ & $-\mathbf{0 . 1 5})$
\end{tabular}

Skin (epidermal) thinning

$\begin{array}{cccccc}\kappa & 0.17 & -0.06 & 0.12 & 0 & 0.17 \\ 95 \% \mathrm{CI} & (-0.25 \text { to } & (-0.5 \text { to } & (-0.05 \text { to } & (-0.32 \text { to } & \begin{array}{c}(-0.25 \text { to } \\ \end{array} \\ 0.59) & 0.38) & 0.29) & 0.32) & 0.59)\end{array}$

nSelected dermoscopic signs

Pigmentation

$\begin{array}{cccccc}\kappa & \text { Not } & \mathbf{0 . 5 9} & 0.1 & \mathbf{- 0 . 4 3} & \mathbf{0 . 7 3} \\ 95 \% \mathrm{CI} & \text { applicable } & (\mathbf{0 . 1 9 - 1 )} & (-0.28 \text { to } & \mathbf{( - 0 . 8 7} \text { to } & (\mathbf{0 . 3 9} \text { to } \mathbf{1})\end{array}$

Granularity

$\kappa$

$95 \% \mathrm{CI}$

\subsection{9}

(0.19-1)

$$
\begin{aligned}
& \text { Not } \\
& \text { applicable }
\end{aligned}
$$$$
0.05
$$$$
(-0.3 \text { to }
$$$$
0.39)
$$

$$
-0.75
$$$$
0.32
$$$$
\text { (- } 1 \text { to }
$$$$
-0.3)
$$

Scaling

$$
\kappa
$$

$95 \% \mathrm{CI}$

$$
\begin{array}{ll}
0.1 & 0.05 \\
(-0.28 \text { to } & (-0.3 \text { to } \\
0.48) & 0.39)
\end{array}
$$

Not

applicable

0

$(-0.48$ to

$0.48)$
Not $\quad-0.17$
applicable $\quad(-0.64$ to
$\begin{array}{lll}-0.43 & -0.75 & 0\end{array}$
$(-0.87$ to $\quad(-1$ to $\quad(-0.48$ to
$\left.\begin{array}{lll}\mathbf{- 0 . 0 0 1}) & -\mathbf{0 . 3} & 0.48\end{array}\right)$

White patchy areas

\begin{tabular}{clcccc}
$\kappa$ & $\mathbf{0 . 7 3}$ & 0.32 & 0.1 & -0.17 & Not \\
$95 \% \mathrm{CI}$ & $(\mathbf{0 . 3 9 - 1})$ & $(-0.15$ to & $(-0.28$ to & $(-0.64$ to & applicable \\
& & $0.8)$ & $0.48)$ & $0.29)$ & \\
\hline
\end{tabular}

Only cases of chronic GvHD are included in the analysis CI Confidence interval

Values in bold indicate statistically significant correlations 
[28]. The dots present in lichen planus are usually tiny and gray-bluish in color over a bluish background, while in ashy dermatosis they usually brownish and larger [28]. Such differences result from the different level of melanophages/melanin deposits (superficial dermis vs. deep papillary and reticular dermis) [28]. Dermoscopically, LPLKs were more likely than non-LPLKs to have scales, orange color, coarse peppering and peppering as the only feature [28].

A trend for an association between collagen bundles in the pathologic examination and white patchy areas or scaling in dermoscopy was also observed. The incidence of whitish patches is significant in lichen sclerosus and indicates atrophy of the epidermis [29] or superficial fibrosis [28], whereas the incidence of fibrotic beams is distinct in morphea, which corresponds to sclerotic dermis [29]. The dermoscopic changes in morphea and lichen sclerosus depend on the phase: inflammatory, sclerotic or atrophic. In the sclerotic phase, dermoscopic findings in the form of white fibrotic beams/white clouds in morphea as well as bright white/white-yellowish patches in lichen sclerosus have been reported to be statistically significantly more frequent [30]. Moreover, among other findings, an important dermoscopic feature of lichen sclerosus is the presence of whitish scaling [30]. White scales typify dermatoses characterized by dry hyperkeratosis (especially parakeratosis), such as psoriasis, lichen planus, discoid lupus erythematous, mycosis fungoides, pityriasis lichenoides chronica, pityriasis rubra pilaris and many others $[10,12,25]$. Linear vessels correspond with multiple diagnosis of lichen planus, mycosis fungoides rosacea, lichen planus, discoid lupus erythematosus, or their presence is due to the epidermal atrophy of any cause $[10,12]$.

Our study has several limitations. Firstly, our study included 20 patients, and larger prospective group is required to corroborate our findings. At this stage of our investigation, we focused mainly on patients with diagnostic cutaneous symptoms of CGvHD in order to establish for the first time the dermoscopic features of this complication. Future studies should focus more on distinctive and other features of CGvHD. Secondly, although the design of the study (clinicopathologic correlation study) did not warrant a control group, it would be valuable to include such a group in future prospective studies of other design to establish the diagnostic accuracy of dermoscopy in GvHD. Lastly, dermoscopic features could be affected by clinical variants of CGvHD and also by the variability resulting from the anatomical sites chosen for dermoscopic assessment.

\section{CONCLUSIONS}

Dermoscopy might be a surrogate for selected clinical and histopathologic signs of GvHD. Clinical classic sclerotic features can be substituted with the dermoscopic signs of pigmentation and white patchy areas. The clinical classic poikiloderma may be linked with the dermoscoptic sign pigmentation, while classic lichen planus-like of mucosa changes might be described dermoscopically by granularity and pigmentation. The presence of melanophages in the histopathologic examination could be predicted by the presence of granularity, scaling and vessels. The appearance of white patches in dermoscopy may predict the absence of lymphocytic infiltration. Given the promising results and the limitations of this study, there is a need for further studies on a larger and more homogenous group of patients. It is possible that such studies would enable the development of a new dermoscopic GvHD assessment scale.

\section{ACKNOWLEDGEMENTS}

We thank the participants of the study.

Funding. No funding or sponsorship was received for this study or publication of this article.

Authorship. All named authors meet the International Committee of Medical Journal Editors (ICMJE) criteria for authorship for this article, take responsibility for the integrity of 
the work as a whole, and have given their approval for this version to be published.

\section{Medical Writing and Editorial Assis-} tance. We thank Anastazja Szlauer-Stefańska (The Department of Bone Marrow Transplantation and Onco-Hematology, Maria SklodowskaCurie National Research Institute of Oncology (MSCNRIO), Gliwice Branch) for linguistic corrections.

Prior Presentation. Poster presentation 5th World Congress of Dermoscopy, Thessaloniki, Greece, 14-16.08.2018. Kamińska-Winciorek G, Mendrek W, Zalaudek I, Jaworska M, Gajda M, Szymszal J, Hołowiecki J, Giebel S: Dermoscopy for the diagnosis of cutaneous graft-versus-host disease (GVHD) after allogeneic hematopoietic stem cell transplantation (alloHSCT).

Disclosures. Grazyna Kaminska-Winciorek, Iris Zalaudek, Włodzimierz Mendrek, Magdalena Jaworska, Maksymilian Gajda, Jerzy Hołowiecki, Jan Szymszal and Sebastian Giebel have nothing to disclose.

\section{Compliance with Ethics Guideli-} nes. Authors have received approval from local ethics committee of Maria Sklodowska-Curie National Research Institute of Oncology (MSCNRIO), Gliwice Branch (reference number $\mathrm{KB} / 430-41 / 13)$. The study was study conducted in accordance with the Helsinki Declaration of 1964, and its later amendments. All subjects provided informed consent to participate in the study as well as for publication.

Data Availability. The datasets generated during and/or analyzed during the current study are available from the corresponding author on reasonable request.

Open Access. This article is licensed under a Creative Commons Attribution-NonCommercial 4.0 International License, which permits any non-commercial use, sharing, adaptation, distribution and reproduction in any medium or format, as long as you give appropriate credit to the original author(s) and the source, provide a link to the Creative Commons licence, and indicate if changes were made. The images or other third party material in this article are included in the article's Creative Commons licence, unless indicated otherwise in a credit line to the material. If material is not included in the article's Creative Commons licence and your intended use is not permitted by statutory regulation or exceeds the permitted use, you will need to obtain permission directly from the copyright holder. To view a copy of this licence, visit http://creativecommons.org/licenses/by$\mathrm{nc} / 4.0 /$.

Open Access. This article is licensed under a Creative Commons Attribution-NonCommercial 4.0 International License, which permits any non-commercial use, sharing, adaptation, distribution and reproduction in any medium or format, as long as you give appropriate credit to the original author(s) and the source, provide a link to the Creative Commons licence, and indicate if changes were made. The images or other third party material in this article are included in the article's Creative Commons licence, unless indicated otherwise in a credit line to the material. If material is not included in the article's Creative Commons licence and your intended use is not permitted by statutory regulation or exceeds the permitted use, you will need to obtain permission directly from the copyright holder. To view a copy of this licence, visit http://creativecommons.org/licenses/by$\mathrm{nc} / 4.0 /$.

\section{REFERENCES}

1. Apperley J, Masszi T. Graft versus-host disease. In: Apparley J, Carreras E, Gluckman E, Masszi T, editors. Haematopoietic stem cell transplantation. The EBMT handbook. 6th ed. Tokyo: Chugai; 2012. p. 217-33.

2. Vogelsang GB. How I treat chronic graft-versus-host disease. Blood. 2001;97:1196-201.

3. Shulman HM, Sullivan KM, Weiden PL, et al. Chronic graft versus host syndrome in man. A longterm clinicopathologic study of 20 Seattle patients. Am J Med. 1980;69:204-17. 
4. Filipovich AH, Weisdorf D, Pavletic S, et al. National Institutes and Health consensus development project on criteria for clinical trials in chronic graft-versus-host disease: I. Diagnosis and staging working group report. Biol Blood Marrow Transplant. 2005;11:945-56.

5. Jagasia MH, Greinix HT, Arora M, et al. National Institutes of Health consensus development project on criteria for clinical trials in chronic graft-versushost disease. Biol Blood Marrow Transplant. 2015;21:389-401.

6. Kaminska-Winciorek G, Czerw T, Kruzel T, et al. Dermoscopic follow-up of the skin towards acute graft-versus-host-disease in patients after allogeneic hematopoietic stem cell transplantation. Biomed Res Int. 2016;2016:4535717.

7. Hillen U, Häusermann $\mathrm{P}$, Massi D, et al. Consensus on performing skin biopsies, laboratory workup, evaluation of tissue samples and reporting of the results in patients with suspected cutaneous graftversus-host disease. J Eur Acad Dermatol Venereol. 2015;29:948-54.

8. Shulman HM, Cardona DM, Greenson JK, et al. NIH Consensus development project on criteria for clinical trials in chronic graft-versus-host disease: II. The 2014 Pathology Working Group Report. Biol Blood Marrow Transplant. 2015;21(4):589-603.

9. Jackson J, Smart C. Graft versus host diseases. Expert consult diagnostic pathology. Non-neoplastic dermathopathology edit. Hall: Cockerell Elsevier; 2017.

10. Errichetti E, Zalaudek I, Kittler H, et al. Standardization of dermoscopic terminology and basic dermoscopic parameters to evaluate in general dermatology (non-neoplastic dermatoses): an expert consensus on behalf of the International Dermoscopy Society. Br J Dermatol. 2020;182: 454-67.

11. Zalaudek I, Lallas A, Moscarella E, et al. The dermatologist's stethoscope-traditional and new applications of dermoscopy. Dermatol Pract Concept. 2013;3:67-71.

12. Lallas A, Giacomel J, Argenziano G, et al. Dermoscopy in general dermatology: practical tips for the clinician. Br J Dermatol. 2014;170:514-26.

13. Lallas A, Argenziano G, Apalla Z, et al. Dermoscopic patterns of common facial inflammatory skin diseases. J Eur Acad Dermatol Venereol. 2014;28: 609-14.

14. Landis JR, Koch GG. The measurement of observer agreement for categorical data. Biometrics. 1977;33: 159-74.
15. $\mathrm{R}$ Core Team. A language and environment for statistical computing. 2016. Vienna: R Foundation for Statistical Computing. http://cran.r-project.org.

16. Kaminska-Winciorek G, Giebel S, Lange D, et al. Dermoscopy in near-full facial transplantation. J Am Acad Dermatol. 2015;72:S19-21.

17. Szlauer-Stefańska A, Kamińska-Winciorek G, Giebel S. Onychoscopy of non infectious nail abnormalities in patients after allogeneic haematopoietic stem cell transplantation. J Eur Acad Dermatol Venereol. 2019;33:637-42.

18. Basilio FMA, Werner B, Mulinari-Brenner F. Permanent alopecia as a manifestation of chronic graft-versus-host disease of the scalp: clinical, dermoscopic and histopathological observations. Clin Exp Dermatol. 2018;43:948-9.

19. Barreiro-Capurro A, Mascaró JM, Galindo BA, et al. Clinical and dermoscopic evaluation of melanocytic lesions in patients with chronic graft versus host disease. Acta Derm Venereol. 2019;99:777-82.

20. Paczesny S, Hakim FT, Pidala J, et al. National Institutes of Health consensus development project on criteria for clinical trials in chronic graft-versushost disease: III: the 2014 Biomarkers Working Group report. Biol Blood Marrow Transplant. 2015;21:780-92.

21. Lee SJ, Wolff D, Kitko C, et al. Biology of blood and marrow transplantation measuring therapeutic response in chronic graft-versus-host disease. National Institutes of Health consensus development project on criteria for clinical trials in chronic graft-versus-host disease: IV. Biol Blood Marrow Transplant. 2015;21:984-99.

22. Wolff D, Schleuning $M$, von Harsdorf $S$, et al. Consensus conference on clinical practice in chronic GvHD: second-line treatment of chronic graft-versus-host disease. Biol Blood Marrow Transplant. 2011;17:1-17.

23. Pinzani C, Bouaziz JD. Blaschkolinear lichen planus pigmentosus in the setting of chronic graft-versushost disease. Acta Derm Venereol. 2019;99:218-9.

24. Braun RP, Gaide O, Oliviero $M$, et al. The significance of multiple blue-grey dots (granularity) for the dermoscopic diagnosis of melanoma. Br J Dermatol. 2007; 157:907-13.

25. Errichetti E, Stinco G. Dermoscopy in general dermatology: a practical overview. Dermatol Ther (Heidelb). 2016;6:471-507.

26. Güngör Ş, Topal IO, Göncü EK. Dermoscopic patterns in active and regressive lichen planus and 
lichen planus variants: a morphological study. Dermatol Pract Concept. 2015;5:45-53.

27. Liopyris K, Navarrete-Dechent C, Dusza SW, et al. Clinical and dermoscopic features associated with lichen planus-like keratoses that undergo skin biopsy: a single-center, observational study. Australas J Dermatol. 2019;60:e119-26.

28. Errichetti E. Dermoscopy of inflammatory dermatoses (inflammoscopy): an up-to-date overview. Dermatol Pract Concept. 2019;9:169-80.
29. Shim WH, Jwa SW, Song M, et al. Diagnostic usefulness of dermatoscopy in differentiating lichen sclerous et atrophicus from morphea. J Am Acad Dermatol. 2012;66:690-1.

30. Errichetti E, Lallas A, Apalla Z, et al. Dermoscopy of morphea and cutaneous lichen sclerosus: clinicopathological correlation study and comparative analysis. Dermatology. 2017;233:462-70. 